\title{
Philosophical Ethnography: or, How Philosophy and Ethnography Can Live Together in the World of Educational Research ${ }^{1}$
}

\author{
FEINBERG, Walter*
}

\begin{abstract}
This essay explores a disciplinary hybrid, called here, philosophical ethnography. Philosophical ethnography is a philosophy of the everyday and ethnography in the context of intercultural discourse about coordinating meaning, evaluation, norms and action. Its basic assumption is that in the affairs of human beings truth, justice and beauty are not ultimate and fixed ends but, as Dewey would have it, guideposts hopefully to more refined considerations and more adequate appreciation and decisions. Philosophical ethnography takes its cue from practice in the post-modern world where intermingling of traditions, fragility of identities, a surplus of critiques and a loss of confidence characterize that world in foundational rationality and traditional liberal institutions. It offers to these traditions and identities a sense of exploration and a possibility for expansion and development. It offers to rationality greater texture, and to liberalism, a more expansive range of acceptable ways of life.
\end{abstract}

What is your aim in philosophy? To show the fly the way out of the fly bottle. Ludwig Wittgenstein, Philosophical Investigations

\section{Introduction}

In a review of my recent book, For Goodness Sake, Murray Thomas writes that

"Walter Feinberg stepped out of his role as a professor of philosophy of education in order to provide a tour of education in religious schools" (Thomas 2006) In one sense he is quite right the goal of that book is to provide the reader with a better understanding of the connections that are to be found between religious instruction and moral education in private religious schools in the United States. ${ }^{2}$ In writing the book, however, I did not feel that I was abandoning philosophy but rather broadening its application by including ethnographic methods into a philosophical conversation. This method will be familiar to those who are aware of my work on Japan (Feinberg 1993) and in this paper I would like to discuss the method, which I call philosophical ethnography, in more detail. I am using the term to suggest an under-exploited disciplinary hybrid that is begin-

\footnotetext{
* The University of Illinois at Urbana-Champaign, Department of Educational Policy Studies, College of Education e-mail address: wfeinber@uiuc.edu
} 
ning to emerge in educational research and that may have potential for helping to coordinate action in cases of inter cultural contact, while minimizing opportunities for manipulation or systematic distortion.

The idea of a philosophical ethnography is part of a philosophical tradition, one that includes people as diverse as James, Dewey, Mead and Durkheim, as well as contemporary theorists such as Habermas, Taylor, MacIntyre and Glover. ${ }^{3}$ These theorists seek to understand and refine everyday practice and local understandings, and they hold that philosophy needs to be grounded in the activities, understandings and problems of everyday life. They all refuse to take the naturalistic "fallacy" seriously but allow that we are always involved in normative activity, that we can never completely separate fact from value and that the problem of postmodern living involves an awareness that the lives we live could have been lived otherwise.

However, until confronted by the taken-for-granted assumptions of another tradition, the normative character of action may be concealed. Where shared meaning is thick among the actors, background assumptions serve to advance coordinated activity providing the goals, motivations and understandings that support coordinated action. Where shared meaning is thin among the actors, coordinated action requires that some of these assumptions be brought to the surface and their connections restructured. While each of these thinkers has prepared the conceptual ground for the method here I describe some of the factors that may be involved in the application of the approach. Hence, in part this paper is an invitation to join a discussion and to help refine the method, and its techniques. In other words, it is as open ended as the method itself.

As a hybrid philosophical ethnography is not a replacement for either philosophy or ethnography. It can be useful in circumstances where a single act or series of acts may carry competing meanings for different cultural groups, and where meanings and values may need to be negotiated. Applied philosophy is useful in assessing the ethics of possible courses of action where meaning is clear and undisputed. It can, for example, provide innovative ways in which to think about educational issues such as affirmative action, corporal punishment, equal opportunity, classroom dialogue, and the like, but it relies on a more or less shared understanding of the meaning of an act. It is less helpful where the nature of an act is in contention because it engages different cultural assumptions. Whether failing to look the teacher in the eye is a sign of dishonesty or respect, whether helping a fellow classmate on a test is cheating or cooperation, whether an exaggeration is a story or a lie depends on the subjective expectations, the objective opportunities, and intersubjective understandings available in the culture. In these cases it takes more than a philosophical argument to make the right call. It is precisely these expectations, opportunities and understandings that ethnographers are trained to reveal. However, ethnography ends where judgment begins. Whether out of concern for the integrity of their study or for the autonomy of their subjects, ethnographers attempt to avoid making judgments about the right thing to do. Their responsibility is to understand the standpoint of the other and avoid importing "their" own norms into their research in ways that could interfere with this task.

Philosophical ethnography, as I am using the term, is a methodological hybrid that uses interviews and observations to identify normative issues, to map out the meaning systems-- rules, common intra-cultural understandings, shared aims, etc-- in which they are imbedded, and, where necessary, to help unblock cultural road-blocks to coordinated action. It addresses situations in which individuals find that they must navigate between different meaning systems in order to arrive at a norm-governed action but where there is tension between different cultural norms. In other words, it is a method of analysis that could be especially useful in many of the educational 
situations that arise within an evolving global society where people from different backgrounds and traditions must engage with each other on a day to day basis, and where there is good reasons and a desire to do so.

The cases where the method is applicable must be distinguished from those in which just a conflict of interest is involved. A conflict of interest entails disagreements about the goals that should be pursued. Cultural confusion, which may result in conflict, suggests deep differences about meaning. Conflicts of interests require techniques of conflict resolution where meanings and goals are adequately understood. Conflicts of meaning require a normatively sensitive ethnography and a culturally sensitive philosophy; It requires, in other words, a philosophical ethnography.

\section{Rethinking the Concept of Culture in an Age of Interaction}

Wittgenstein's observation that the task of philosophy is to show the fly the way out of the fly bottle articulates an important moral program for philosophy. However, if taken in a certain way, it also reinforces a common, but somewhat misleading understanding of the relationship between culture (the fly bottle) and freedom (the way out). The moral task is to enable individuals to escape from the conceptual traps that language conceals. The problem is (as Wittgenstein well understood) that language is not independent of culture and, whatever the merits of Wittgenstein's work as a whole, the metaphor of the fly in the fly bottle suggests that people dwell in a culture and that they dwell in only one culture at a time.

In the postmodern world where people employing different cultural practices come into contact, they conflict with one another, they negotiate meanings, they borrow from one another and they create new meanings. In doing so, they draw first from one meaning system and then from another. In this world it is useful to think of culture as involving webs of shared meaning (rather than as containers) composed of strands that include the utterances, gestures, expressions, etc. that individuals issue and that other individuals understand in functionally appropriate ways. Where coordination is reasonably easy to facilitate the mutual associations will be tighter and deeper than where coordination is more difficult. When the web is sufficiently thick so that a purpose can be accomplished with little explanation we speak of a "culture". However, depending on the scope of the purpose the depths of the culture may vary. Hence a computer language may suggest a relatively thin culture, one that serves a narrow range of purposes whereas a natural language suggests something more robust because it can set the conditions for a wide range of coordinated actions. The word "culture" indicates associations in which strands are connected more directly to each other. When we speak of different cultures we are marking associations that are more or less direct connections in one meaning system but indirect in another. Geertz explains the idea of culture as a web of meaning (Geertz 1973)

The Concept of Culture I espouse ... is essentially a semiotic one .... Man is an animal suspended in webs of significance he himself has spun. I take culture to be those webs, and the analysis of it to be therefore not an experimental science in search of a law but an interpretive one in search of meaning. ${ }^{4}$

I want to add to Geertz that people participate in these webs at various points and with varying degrees of familiarity. When we speak of a "culture" we mean a group of people who share 
tightly woven segments of that web. The implication is that various strands of that web may be shared by other people but in a more or less loosely woven fabric. Thus we might productively think of a single "culture" as a way of speaking about an especially thick segment of shared meanings, (coordinated associations and a communal sense of significance) that can serve a broad range of purposes in specific ways. I put quotes around the word culture to indicate that it indicates separable practices tied together in a more or less coherent way and which people appropriate to different degrees. "Culture" then is actually a short hand for practices that allows for different degrees of understanding and different levels of participation. ${ }^{5}$ These practices may then be disaggregated as when we speak say of linguistic practices, religious practices, and educational practices, as bundled into a single culture.

A shared meaning exists whenever two or more people employ the same set of background assumptions to understand an act, including acts of speech. When individuals share a wide range of assumptions across a number of practices, they may be said to belong to the same culture. However, the idea that the background assumptions of any two members of a "group" of "individuals" overlap completely is inconsistent with the facts of modern life and probably developed because early concepts of culture were employed by European anthropologists to study groups that had, until colonialism, been isolated from Europe. (Although not necessarily from other non-European groups.) Shared meaning allows activity to be coordinated through time and space. A hammer is a nail sinker because of a collective history where first iron, then nails is invented, projects are anticipated and tools appropriated to carry them out. Activities are coordinated through space as other people grasp the rules that are attached to an act. A twitch, to use Ryle's example, is not meaningful until it becomes a wink, or, until it is attached to a purposeful action, to a rule that others can come to share. (Geertz, 1973, p.6)

Significance refers to the specific standpoint of the person to whom something has $A$ meaning. When we take this standpoint for granted, meaning is thought of as reference. However, strictly speaking there is no reference without a standpoint. The morning star and the evening star, to use a classic philosophical example, refer to the same astronomical phenomenon, but they have different meanings because of where we stand in relation to them. In order for an event to be meaningful it needs to be a part of a series of acts that together make up a project. The evening star suggests say, a candle-lit dinner, the morning star, a shower and a day at the office.

It is useful for practical purposes to think of a culture as a map that lays out all of the possible connections that a discrete action can have to agent/audience, (remembering, of course that agent and audience change places). In one setting a smile might mean amusement, and interpreted within the grid related to friendship. In another it might be a come-on and interpreted with the grid related to flirtation. In another setting, say the military, a smile might mean insubordination and interpreted within a grid having to do with hierarchy. To use culture as a map in this case is to have available the range of possible meanings that a smile can have for a specified group of people in a certain context. A breakdowns in meaning occurs within a culture when the actors do not realize that they have different connections in mind.

In order to mend a breakdown within a cultural formation, past behavior must undergo a reinterpretation and some acts will be seen to have different connections than originally thought. Your companion is watching out for poison ivy, you thought he was looking for deer tracks. You spot a deer. He spots a cluster of poison ivy that happens to have a deer standing on it. You advance quietly for a closer look; He makes a noisy retreat. The presence of the cultural map provides an opportunity to mentally retrace the miscues and share the differing understandings. We 
often call this interpretation. Interpretation is the process of grasping the point of seemingly incoherent acts and understanding them anew as a series with an end in view. Noisily backing away is incoherent from the point of view of the purpose of a close inspection of the deer. Interpretation occurs within a shared set of background meanings and involves making obvious the point of an activity that was previously obscured.

What we call culture includes the shared rules required for coordination as well as the procedures and otherwise taken-for-granted meanings needed to repair breakdowns in coordination. Strictly speaking, however, no two individuals, even when raised in the "same" environment share all strands of meaning, and thus no two individuals, share the exact same culture. Some experience will remain primary for one person and derivative for another. The first child does not experience the family in exactly the same way as the second and there are some experiences that second children from different families may share that they do not share with their older siblings. In other words, something always remains to be explained even as the concepts used to develop the explanation are themselves circumscribed within cultural formations. Where frequent elaboration and explanation of many practices is required, we often refer to people as belonging to different cultures. This means that they share a comparatively small number of meaning strands. An explanation then involves seeking the relatively few strands that are held in common in order to build up an understanding of strands that are not. There is never just one explanation of a phenomenon. All explanations take into account the standpoint and background understanding of the listener, and given the possibility of different standpoints and understanding, explanations will differ. In contrast to the act of rendering an interpretation which, when meaning breaks down, looks forward to the point of the activity, explanation looks backwards to seek the shared strands of meaning upon which new understanding can be grafted. Most theories of scientific explanation miss this important step. What counts as an explanation for one person will differ from what counts as one for another depending on background understanding.

Take the example Hemple advances as "an explanation" of the reason mercury in a glass thermometer falls before it rises when heat is applied. In Hemple's explanation it is sufficient to explain the phenomena in terms of the effect of heat on different materials. However, a certain level of implicit understanding is critical if this explanation is to be understood. For example, a person needs to be able to "see" the glass and the mercury as two separate materials in order to understand the object of the explanation, and it is possible that a useful explanation would require teaching "how to see the thermometer." Hemple's example already draws on a shared standpoint, but that standpoint itself rests on a thick layer of cultural understanding (Hemple 246).

Because human beings share certain features with all other human beings-we all have to sleep, eat, we all have language, etc. there are always some assumptions that are shared among different individuals, although given two different sets of individuals these may not always be the same. When spoken language fails, gestures may allow us to communicate a thinner, more simplified meaning. Once, when in a restaurant in Spain, after five minutes of fumbling for the Spanish word for "fish" a word that I recall last hearing in high school, I was able to get the waiter to understand by feigning the crawl stroke of a swimmer. However, I could not get him to understand that I wanted my fish broiled, not fried and that I would prefer salmon, not cod. These areas of overlapping meanings, both those attached to specific meaning strands and those attached to more global experiences, make translation, however difficult, and however simplified, always a possibility.

The map analogy is useful in correcting the image that cultures exist as self-sealed containers and in allowing us to analyze continuities and discontinuities across different "systems" of 
meaning. However, there are limits to the map metaphor as well. Maps, after all, are simply tools and once they are used we have little use for them and they go back in the draw. Yet people care about their culture. Often cultural norms go unquestioned from the inside, and when outsiders behave according to different norms, they are seen as strange or worse. Our cultures lend significance to our lives. They not only mark our standpoint and thus determine what is meaningful in some abstract, theoretical way. They mark meanings as important lending significance to the standpoint that we inherit. In modern societies people from different meaning formations are involved with one another in different ways, and they care about whether their social environment advantages or disadvantages their understandings.

\section{Examples of Philosophical Ethnography in use}

Philosophical ethnography acknowledges with conventional ethnography that traditional norms serve to anchor peoples' lives and that understanding such norms requires an understanding of the ways in which they work in context. However, it also allows with, applied philosophy, that norms are revisable in light of critical reflection. There are two kinds of cases where I have found philosophical ethnography to be useful. The first involves the following: Contact between people from two or more "cultures" or separate meaning "systems" where a normative issue is identifiable, and where the need for coordinated action requires cultural differences be addressed and where there is benefit to be gained from and a desire to maintain a level of internal cultural coherence. But, where continuous and increasing contact between the different cultural forms is likely. The situation differs from the paradigm of the classical ethnographer in that it assumes cultural contact, not separation as normal and assumes a situation where coordination with members of another cultural formation may be desirable and mutually beneficial. It differs from the situation of the applied philosopher because it cannot take for granted the existence of a significant body of shared norms. The task is not simply to address a single ethical problem, but to reconstruct practice in cases where conventional activity has become problematic as a result of intercultural engagement.

The second kind of situation involves a single person who is committed to two different and conflicting systems of meaning and beliefs and must decide upon a course of action that seems inconsistent with one of them. The problem then is whether one set of meanings can be affirmed without disowning the other. In contrast to the first situation where one meaning system is quite foreign to the practitioners of the other, here the two competing systems dwell within the same person.

These two situations are admittedly different but since the idea of "culture", defined in terms of the density of shared meaning, is rather open ended, it is important that we not be too restrictive in what we identify as a cultural group. To a large extent what counts as "culture" will depend on the context and purpose in which meaning is employed. When the German and the American mechanic are engaged in fixing a car, even though in other respects they may share few strands of meaning, their car culture may be relatively thicker than that shared with mechanical illiterates from their own respective countries. The test then of whether philosophical ethnography is likely to be useful is whether in a given situation there are competing practices that can be tracked back to different taken for granted systems of meaning. Because the concept of culture used here is fluid, relating to the background meaning required for successful communication in 
given situations, the object for the application of philosophical ethnography may be quite narrow, as in the case of the car culture, or it may be quite broad, as say in the cultural differences involved say, the meaning of lifetime employment in Japan (community, mutual obligation, caring, etc.) and the United States (limiting competition, protectionism, etc.)

\section{Philosophical Engagements with other Cultures}

Philosophical ethnography requires a considerable degree of self-reflection because the researcher is likely to view the object from her own cultural perspective. An analogy is the justification for the requirement that candidates for psychoanalysis need themselves to undergo analysis. It is seen as a way to minimize distortions in their diagnosis that could arise out of their own unresolved neurosis. There are at least two reasons for self-reflection in philosophical ethnography. The first involves misunderstandings on the part of the subject about the nature of the research process and then, as a result of assuming that both researcher and subject are on the same page, a misunderstanding by the researcher of the way the subject is understanding the process. Here there is a need to calibrate the discourse of researcher and subject so as to assure that each understands the process in a similar way and that power differences can be minimized without compromising either the goals of the project or of the research. The issue arises because philosophical ethnography aims to help improve decisions, but it may be unclear just who the beneficiary of the research should be.

The second misunderstanding begins with the researcher and involves the inadvertent imposition of the researcher's meaning onto subject's initiated acts. This is a problem of context where the aim is to recognize this as an act of unintended symbolic imposition and to work towards developing an account that reflects the subjects meaning. Resolving the problem of context involves placing the act within the assumptions of normality that are prominent in the subjects meaning system. Below are examples of each of these problems.

\section{Calibrating the Moral Discourse regarding research}

A researcher is always involved in a normative research community that is different in important ways from the communities being studied (Winch 1960), and sometimes the focus of attention must be turned back on the cultural norms of research itself. This may be as much the case in near objects as in distant ones as misunderstandings and conflicting expectations may arise in either kind of study. When this happens, and if power relations are to remain within reasonable bounds, then researcher and researched need to analyze the way in which their different cultures/ taken-for-granted meanings generate different expectations.

Think for example of the clinical psychologists whose client begins to think of the clinician as friend not therapist and thereby expects to have the bill forgiven. "After all, friend's don't charge for helping one another". A well trained psychologist, after assessing the client's ability to pay, may find a need to bring the norms of the relationship into focus and attempt to get an agreement on them-"this is therapy, not friendship". Similar kinds of issues can arise in cases of philosophical ethnography where one of the critical objects of research is the negotiation of norms across different meaning systems. Given the possibility for misunderstanding it is necessary for the 
researcher to reflect on her own behavior as a cultural product, and, if possible, to talk about the issue with those who are the objects of the researcher's study.

Philosophical ethnography thus must be sensitive to normative issues raised within the context of the study itself, and view them as possible objects of research. For example, a colleague and I were invited by a community educational group composed of teachers, parents and union leaders to research its attempt to widen minority participation in decision-making regarding their local schools. While the group did not support the research financially (our University supported it), we felt quite indebted to them for opening their meetings to us and inviting us to study the process. However, over time they would quite innocently refer to us as "consultants", a term that concerned us, because it implied that we were there only to advance their end while there were other interests at stake as well and other definitions (including those of some minority organizations) of participation.

When a sarcastic remark was made in our presence about our reluctance to provide guidance, we felt obliged to talk with the group about our discomfort, and to discuss the conflicting expectations that had developed. We had one meeting where we discussed some of the differences between being a consultant and being a researcher, as we each understood the term, and came to some resolution of the issue. We negotiated some areas where we could be of help-- sharing our notes of their meetings with them, providing them and any other interested group with the history we had done of race relations in the community, helping them with a survey they wanted to do of parental attitudes. The general rule that we came up with was that we could help them in ways that could be shared with other groups in the community, or in recording material about their own deliberations. We did not feel that we could help them in ways that advanced their goals over those of other groups in the community that we would be in contact with. In the end both they and we came to an understanding about the different limits and expectations placed on researchers and consultants. While such issues are not uncommon in research, they often are worked out at the sidebar and are not seen as central to the study itself. In this case, the episode became a component of the written study showing how the researcher is imbedded in a cultural network and as a lesson about how cultural norms might become objects for mutual deliberation.

\section{Defining the Problem: Is it a "Sin"?}

Some of my research has taken place in religious settings and here practical judgment sometimes corrects for the excessive logic chopping of official doctrine. Nurses in Catholic hospitals, for example, are expected to be committed to the equal worth of all life. While this does not mean that they must always use heroic methods to revive a patient who would otherwise die, it does mean that they are expected to respect the patient's or the family's wishes to do so. Yet some have told me that they walk a bit more slowly when the monitors show that it is the heart of a ninety year old stroke victim that has stopped beating than they do when it is he heart of a twenty year old. Hence in the slowness of their pace do they make a judgment about the relative value of an existing life.

Once we understand some of the ways in which people cope with conflict, we can then begin to address the normative system on a more general level, exploring not only the meaning system but also the various ways in which it is appropriated. Such an analysis can provide an inventory of innovative responses that people use to satisfy conflicting cultural imperatives. 
Part of the task of the philosophical ethnographer is to map out these different conceptual schemes while identifying the way they are incorporated by different parties. An adequate mapping requires knowledge of the theories in which the discourses are embedded, as well as an observational and interview approach that allows the participants to communicate the way in which they make sense of their world of practice to one who does not necessarily share their meaning. Thus, the particular event is tied in a concrete way to larger, theoretical units of understanding that gives the event its meaning. There is of course is no final map, and initial maps can always be refined or revised. Often, there is no need to go any further than to display the different ways in which people appropriate the conflicting discourse to work out the immediate problems that confront them. Here the philosophical ethnographer serves a function much like a jurist, adding to the body of cases that people may draw upon to address difficult new litigation.

At other times philosophical ethnography may be used to recalibrate theory with practical experience and may require reexamination of practice or a reinterpretation of theory. Consider, for example, the implicit negotiations occurring within Catholics texts over the nature of $\sin$. Is sin the punishment of an angry God that damns the sinner to the fires of hell or, is sin the psychological longing that occurs when we are separated from God? The older Catechism emphasizes the former; the newest one stresses the latter, although neither explicitly rejects the other. In the most recent Catechism, Hell "is the state of self-exclusion from communion with God." (Catechism of the Catholic Church, 1997). In this Catechism the mention of eternal fire is brief (Catechism 1997). And the term is set off by quotation marks as if to say, well yes, the Church has held to the idea of damnation by fire, but it might be understood metaphorically. In other words, the quote allows for an interpretive moment. Compare this to the description of the plight of the damned found in the 1897 Baltimore Catechism now on the web. "Here the damned suffer the most frightful torment in all their senses. The worst suffering you could imagine would not be as bad as the sufferings of the damned really are." (Baltimore Catechism, original 1894 on line at http://www.catholic. net/RCC/Catechism/Doit.html) The understanding of the nature of sin has also been influenced by modern psychology. For example, in the 1997 edition Masturbation is not described as sin but as an "offense against chastity." Just how serious an "offense" is said to be dependent on maturity force of acquired habits and "conditions of anxiety, or other psychological or social factors that can lessen or even reduce to a minimum, moral culpability." (Catechism 1997).

That these issues are still matters of negotiations may be surmised by the enigmatic introduction to the Baltimore Catechism on the web page. "The Baltimore Catechism is a timeless classic. The only changes that have been made in the Church, since it was written, are those of discipline. No changes have been made in the area of doctrine and morality." (Baltimore Catechism) ${ }^{\mathrm{v}}$ But how are we to take this introduction. On the one side, a timeless classic places it as much in the realm of literature as theology, and given the most recent glosses on sin and damnation differences in discipline would seem to be as significant as differences in doctrine.

\section{Conclusion}

Philosophical ethnography is a philosophy of the everyday and ethnography in the context of intercultural discourse about coordinating meaning, evaluation, norms and action. Its basic assumption is that in the affairs of human beings truth, justice and beauty are not ultimate and fixed ends but, as Dewey would have it, guideposts hopefully to more refined considerations and more 
adequate appreciation and decisions. Philosophical ethnography takes its cue from practice in the post-modern world where intermingling of traditions, fragility of identities, a surplus of critiques and a loss of confidence characterize that world in foundational rationality and traditional liberal institutions. It offers to these traditions and identities a sense of exploration and a possibility for expansion and development. It offers to rationality greater texture, and to liberalism, a more expansive range of acceptable ways of life.

Philosophical ethnography is useful for locating opportunities for productive collaboration in situations in which meaning systems have become frozen, and the consideration of productive alternatives blocked. In these situations it can serve to locate the deeper assumptions that disable the consideration of alternative possibilities. It holds promise for helping people from different cultural groups find the threads upon which new understandings may arise, and new forms of coordination undertaken.

\section{Notes}

1 Appreciation to Eric Bredo, Eammon Callan, Sophie Haroutunian- Gordon, Fazil Rizvi, Rashid Robinson, and Stacy Smith and Jill Wightman for Comments on an earlier draft. This research was partially supported by the Spencer Foundation.

2 All religious schools in the United States are private and, in general, religion is not a part of American public education.

3 My appreciation to Eric Bredo for pointing out this connection.

4 My appreciation to Jill Wightman for reminding me of Geertz view on this point.

5 My appreciation to Fazal Rizvi for suggesting this.

\section{References}

Baltimore Catechism (on-line) http://www.catholic.net/RCC/Catechism/Doit.html

Catechism of the Catholic Church: Second Edition, Revised in accordance with the official Latin text promulgated by Pope John Paul II, Washington: US Catholic Conference, 1997. P. 881

Dalby, L. (1983) Geisha, New York: Vintage

Dombrowsky, D. A. and Deltete, R. (2000). A Brief Liberal, Catholic Defense of Abortion, Urbana: The University of Illinois Press.

Feinberg, W. (1993) Japan and The Pursuit of a New American Identity: Work and Education in a Multicultural Age, New York: Routledge,

\section{Reference Blinded}

Geertz, C. (1973) The Interpretation of Cultures, New York: Basic Books, p. 5.

Geertz, (1984) Anti-anti relativism of the American Anthropologist, vol. 86. pp. 263-278.

Glover, J. (1999) Humanity: A Moral History of the Twentieth Century, New Haven: Yale University Press. p. 323.

Fortes, M. (1953) The Structure of Unilineal Descent Groups. American Anthropologist, v. 55.

Habermas, J. (1972) Knowledge and Human Interest, Boston: Beacon Press,

Hemple, C. (1965) Aspects of Scientific Explanation, New York: Free Press, p.246.

Kroeber, A. L and Kluckhohn, C.. Culture: A Critical Review of Concepts and Definitions, Harvard University Peabody Museum of American Archeology and Ethnography papers, vol. 47, No. 1. Cambridge, Ma:

MacIntyre, A. (1981) After Virtue, Notre Dame, Indiana: University of Notre Dame Press

Moss, P. A. and Schulz, A. "Educational Standards, Assessment, and the Search for Consensus", American Educational Research Journal, Spring, 2001, Vol. 38, No. 1, pp. 37-70.

Resaldo, M. (1982) The Things we Do with Words: Ilongot speech acts and speech act theory in philosophy, Language and Society, Cambridge: Cambridge University Press, Vol. II, 1982.

Said, E. (1979) Orientalism, New York: Vintage.

Seferian, M, (1995) Structure and Culture in the History of Anthropology, unpublished Seminar paper.1995.

Sehr's, D. (1997) Education for Public Democracy, New York: SUNY Press.

Singer, M. (1968) "Culture" International Encyclopedia of Social Sciences, Crowell, Collier \& MacMillan,V. 3.

Smith, S. (2001) The Democratic Potential of the Charter School, New York, Peter Lang

Thomas, M. (2006) Review For Goodness Sake, Teachers College Record, June 05, 2006, http://www.tcrecord.org

Willis, P. (1978) Learning to Labor: How Working Class Kids get Working Class Jobs, Teakfiel Limited: Saxon House.

Winch, P. (1960) The Idea of A Social Science and Its Relation to Philosophy, London: Routledge \& Kegan Paul. 